\title{
Prosodic comprehension and expression in schizophrenia
}

\author{
D Murphy, J Cutting
}

\begin{abstract}
Schizophrenics, manics, depressives and normal subjects (15 in each group) were tested for their ability to understand and express the prosodic quality of speech. Sentences in which one word was stressed (stress prosody comprehension) or in which a particular emotion was conveyed (emotional prosody comprehension) were taped and played to subjects to test their comprehension. Subjects were then asked to read out a list of sentences either stressing a nominated word (stress prosody expression) or conveying a nominated emotion (emotional prosody expression), and their efforts were rated by a panel of normal raters. The main results were 1) that schizophrenics were significantly inferior to the normal group, but equivalent to manics and depressives on emotional prosody comprehension; 2) schizophrenics were significantly inferior to all other groups on emotional prosody expression; and 3) all four groups were equivalently proficient on stress prosody comprehension and expression. The results are interpreted as lending support for the idea that there is an underlying right hemisphere dysfunction in schizophrenia.
\end{abstract}

The prosodic quality of speech comprises variations in pitch, intensity and rhythm which affect the intended meaning of what is said without altering the structural characteristics of the phoneme. It is usually divided into "stress prosody" and "emotional prosody". The former element enters decisions about the actual semantic meaning of what we hear. For example, the separate meanings attached to "He saw the bigwig in the shop" and "He saw the big wig in the shop" can only be unravelled by noting whether the main stress falls on "big" or "wig". The latter element contributes to our understanding of what is known as the pragmatic meaning of speech, the intended "between-the-lines" meaning, as it were. A boy hearing his mother say "You're a very naughty boy" can receive entirely different messages depending on whether the accompanying tone is angry or playful.

Neurological interest in prosody has been stimulated recently by the discovery that differently sited lesions have a different effect on prosody, depending on which hemisphere they affect, and on which part of that hemis- phere is affected. Emmorey, ${ }^{1}$ for example, showed that patients with left hemisphere damage, but not those with right-sided damage, had difficulty in distinguishing noun compounds (such as greenhouse) from noun phrases (such as green house). Patients with right hemisphere damage, on the other hand, but not those with left-sided damage, have difficulty in judging whether a speaker is angry, sad or happy. ${ }^{2}$ This suggests that stress prosody is a function of the left hemisphere, while emotional prosody is subserved by the right hemisphere. Ross ${ }^{3}$ claimed that, in the latter case, an anterior lesion mainly affected expressive prosody and a posterior lesion mainly affected receptive prosody, thus mirroring the location of propositional language in the left hemisphere.

Psychiatric interest in prosody has also been evident in the past decade, with several investigators claiming that schizophrenics are impaired at recognising different emotional intonations in the speech of others ${ }^{45}$ and at conveying these in their own speech, as judged by normal raters. ${ }^{67}$ The situation for manics or depressives has not been systematically investigated.

The impetus for this study was the observation that the pattern of prosodic impairment reported in schizophrenia was the same as that found in patients with right hemisphere lesions. If this is true, it would provide further evidence for the thesis of one of the authors that some of the phenomena of schizophrenia arise from right hemisphere dysfunction, of an as yet unknown cause. ${ }^{89}$ The studies on schizophrenic prosody to date, however, are not rigorous enough to allow us to make a comparison in this respect between schizophrenia and definite right hemisphere damage with any certainty. For example, it is not clear if the impairment in schizophrenic prosody is specific to the emotional component. If it also affected stress prosody, then this would, according to the neurological literature mentioned above, imply that left hemisphere functions were also involved. Moreover, it is not clear if schizophrenics differ from other psychotic groups, for example manics or depressives, in the pattern of their prosodic impairment. It was these questions which this study was designed to answer.

\section{Method}

Subjects

Fifteen schizophrenics, 15 manics, 15 depressives and 15 normals were included in the experiment. The schizophrenics who agreed to 
cooperate were consecutive admissions to the Bethlem and Maudsley Hospitals, diagnosed according to the Research Diagnostic Criteria. ${ }^{10}$ They were all on neuroleptics but were still psychotic at the time of testing. The manic and depressive patients were consecutive admissions with mania or a major depressive disorder. ${ }^{10}$ The manics were all on neuroleptics, and the mean equivalent dose of chlorpromazine was not significantly different from that being administered to the schizophrenics. The depressives were all on antidepressants. The normal subjects were members of the hospital staff.

The sex ratio, mean age and premorbid IQ (Nelson Adult Reading Test ${ }^{11}$ ) of all groups are shown in table 1. The IQ of all groups is comparable, even though high. The latter finding probably reflects the overgenerous norms in the Nelson Adult Reading Test's IQ equivalences. The schizophrenics were significantly younger than the manics or depressives.

\section{Procedure}

There were four tests, each comprising 10 sentences:

\section{Comprehension of stress prosody}

One of the authors prepared a tape of himself reading 10 sentences with one of the words emphasised, for example, "I suppose Michael really did love Susan." The subject listened to the sentences and, after each one, was asked to point to the word on a typed sheet of the sentences which he or she thought had been emphasised. A subject's score was the number of correct identifications.

\section{Comprehension of emotional prosody}

The experimenter also taped himself reading out another set of 10 sentences, each in one of four intended emotions-neutral (2), angry (2), surprised (3) or sad (3). The subject listened to each, and was asked to guess which of these four emotions he or she thought the sentence was being read in. All subjects were instructed to select one of these, and no other. A subject's general performance was measured by the number of correct identifications of the intended emotion. The proportions of each emotion correctly identified, and the pattern of falsely named emotions, were also calculated as a guide to the existence of any differential impairment or bias between emotions.

Table 1 General results on comprehension and expression of emotional and stress prosody

\begin{tabular}{|c|c|c|c|c|}
\hline & $\begin{array}{l}\text { Schizophrenics } \\
(n=15)\end{array}$ & $\begin{array}{l}\text { Manics } \\
(n=15)\end{array}$ & $\begin{array}{l}\text { Depressives } \\
(n=15)\end{array}$ & $\begin{array}{l}\text { Normals } \\
(n=15)\end{array}$ \\
\hline $\begin{array}{l}\text { Age-mean } \\
\text { Sex distribution-m: } f \\
\text { IQ-mean }\end{array}$ & $\begin{array}{l}27 \cdot 9 \star \star \\
10: 5 \\
113 \cdot 5\end{array}$ & $\begin{array}{r}37 \cdot 8 \\
8: 7 \\
112 \cdot 6\end{array}$ & $\begin{array}{r}41 \cdot 5 \\
7: 8 \\
109 \cdot 4\end{array}$ & $\begin{array}{r}38 \cdot 2 \\
8: 7 \\
108 \cdot 5\end{array}$ \\
\hline $\begin{array}{l}\text { Prosody results_-mean (SD) } \\
\text { Stress comprehension } / 10 \\
\text { Emotion comprehension } / 10 \\
\text { Stress expression } / 10 \\
\text { Emotion expression } / 10\end{array}$ & $\begin{array}{l}8 \cdot 5(0 \cdot 7) \\
7 \cdot 5^{\star \star}(0 \cdot 8) \\
7 \cdot 5(0 \cdot 7) \\
4 \cdot 3^{\star}(0 \cdot 9)\end{array}$ & $\begin{array}{l}8 \cdot 1^{\star \star}(0 \cdot 7) \\
7 \cdot 9^{\star \star}(0 \cdot 9) \\
8 \cdot 1(0 \cdot 7) \\
5 \cdot 4 \dagger+(0 \cdot 8)\end{array}$ & $\begin{array}{l}9 \cdot 2(0 \cdot 6) \\
7 \cdot 7^{\star \star}(0 \cdot 8) \\
7 \cdot 9(0 \cdot 6) \\
5 \cdot 3+(0 \cdot 9)\end{array}$ & $\begin{array}{l}9 \cdot 0(0.6) \\
8 \cdot 8(0 \cdot 7) \\
7 \cdot 5(0.9) \\
5 \cdot 2(1 \cdot 1)\end{array}$ \\
\hline
\end{tabular}

Significance levels of post hoc $t$ test comparisons between normals and other groups ${ }^{\star} \mathrm{p}<0.05,{ }^{\star \star} \mathrm{p}<0.01$

Significance levels of post hoc $t$ test comparisons between schizophrenics and affective groups:
Expression of stress prosody

A subject was shown 10 sentences, for example, "Wait for me outside the cinema tonight", and asked to read them out emphasising a designated word, for example, outside. Their efforts were taped and, as the designated word was varied between subjects, this allowed a subject's performance on the 10 sentences to be played later to four normal raters (blind to the diagnostic category of a subject) who then wrote down which word they thought had been emphasised. A subject's score was the number of sentences where the raters' decision on the emphasised word corresponded to the one which had been designated to the subject.

\section{Expression of emotional prosody}

A subject was shown 10 sentences, and asked to read each out in one of four designated emotions-normal, angry, surprised or sad. Their efforts were taped, and the designated emotion was varied between subjects, with the proviso that in each group an equal distribution of emotions was aimed at. Four normal raters then listened to the tapes in scrambled order of diagnostic categories and wrote down which of the four emotions they thought was being expressed. A subject's performance on this test was assessed in two ways: 1) the number of designated emotions which did not correspond with the raters' decisions-false negatives (overall and for each emotion separately); and 2) the proportions of those emotions which were falsely identified by the raters-false positives. The first measure was a reflection of which emotional states a subject found difficulty in expressing, the second those emotional states which a subject actually presented to the world.

Inter-rater reliability on the last test was high. Rater one's rank ordering of the normals from best to worst in conveying emotional prosody correlated at a level of $r=0.85$ with rater two's ranking, $r=0.83$ with rater three's ranking and $r=0.86$ with rater four's ranking (Spearman correlation coefficient).

\section{Results}

Analysis of variance with repeated measures was carried out with the four subject groups and the four measures of prosody. Significant differences emerged both between subjects $(\mathrm{F}-$ 2.92; df 3, 56; $P<0.05)$ and within subjects ( $F$ $-3.65 ;$ df 3,$168 ; P<0.05)$. This justified posthoc comparisons between subject groups on each measure.

These results (table 1) demonstrate that schizophrenics were comparable in their performance with all other groups in comprehending and expressing the stressed words. However, schizophrenics were significantly inferior to normal subjects in comprehending and in conveying the emotional tone of a sentence. Schizophrenics were also significantly inferior to manics and depressives in conveying emotional tone but were not significantly different from these two groups in comprehending the emotional tone. 
Table 2 Distribution of errors by emotion on emotional prosodic comprehension task

\begin{tabular}{|c|c|c|c|c|c|}
\hline \multicolumn{2}{|c|}{$\begin{array}{l}\text { Number of subjects in each } \\
\text { group making } 1,2,3, \\
4 \text { errors }\end{array}$} & Schizophrenics & Manics & Depressives & Normals \\
\hline \multicolumn{6}{|c|}{ False negatives (failure to identify designated emotion): } \\
\hline Neutral & $\begin{array}{l}1 \text { error } \\
2 \text { errors } \\
3 \text { errors }\end{array}$ & $\begin{array}{l}4 \\
2 \\
0\end{array}$ & $\begin{array}{l}8 \\
0 \\
0\end{array}$ & $\begin{array}{l}5 \\
1 \\
0\end{array}$ & $\begin{array}{l}6 \\
0 \\
0\end{array}$ \\
\hline \multirow[t]{2}{*}{ Angry } & $\begin{array}{l}1 \text { error } \\
2 \text { errors }\end{array}$ & $\begin{array}{l}2 \\
0\end{array}$ & $\begin{array}{l}4 \\
0\end{array}$ & $\begin{array}{l}1 \\
0\end{array}$ & $\begin{array}{l}1 \\
0\end{array}$ \\
\hline & 3 errors & 0 & 0 & 0 & 0 \\
\hline \multirow[t]{3}{*}{ Sad } & 1 error & 3 & 6 & 5 & 1 \\
\hline & 2 errors & 3 & 1 & 2 & 0 \\
\hline & 3 errors & 1 & 0 & 1 & $\mathbf{0}$ \\
\hline \multirow[t]{2}{*}{ Surprised } & 1 error & 7 & 4 & 4 & $\begin{array}{l}6 \\
2\end{array}$ \\
\hline & $\begin{array}{l}2 \text { errors } \\
3 \text { errors }\end{array}$ & $\begin{array}{l}3 \\
1\end{array}$ & $\begin{array}{l}4 \\
0\end{array}$ & $\begin{array}{l}4 \\
1\end{array}$ & 0 \\
\hline \multicolumn{6}{|c|}{ False positives (emotion stated instead of correct one): } \\
\hline \multirow[t]{4}{*}{ Neutral } & 1 error & 6 & 5 & 4 & 4 \\
\hline & 2 errors & 3 & 5 & 4 & 3 \\
\hline & 3 errors & 2 & 0 & 2 & 0 \\
\hline & 4 errors & 1 & 0 & $\mathbf{0}$ & 0 \\
\hline \multirow[t]{3}{*}{ Angry } & 1 error & 1 & 3 & 2 & 0 \\
\hline & 2 errors & 0 & 0 & 2 & 0 \\
\hline & 3 errors & 1 & 0 & $\mathbf{0}$ & 0 \\
\hline \multirow[t]{2}{*}{ Sad } & 1 error & 7 & 4 & 6 & 5 \\
\hline & 2 errors & 1 & 2 & 1 & 0 \\
\hline \multirow[t]{2}{*}{ Surprised } & 1 error & 1 & 4 & 3 & 3 \\
\hline & 2 errors & 1 & 1 & 0 & 0 \\
\hline
\end{tabular}

Manic and depressive patients were comparable with normal subjects in their ability to convey emotional tone and stress. Both manics and depressives, however, were significantly inferior to the normal group in comprehending emotional tone, and manics were additionally significantly inferior to the normal group in comprehending stress.

A breakdown of the results of emotional prosodic comprehension according to specific emotions is presented in table 2 . No statistical analysis was possible because there were so few errors, but an examination of the numbers of subjects within each group making one, two or three errors on any of the emotions reveals that there is at least one obvious trend: relative to the normal group, all three pathological groups were particularly poor at identifying sadness out of the four emotions. If one examines the distribution of false positives, there is no real suggestion that any of the groups is particularly prone to over-identify any one of the four emotions.

In Table 3 there is a breakdown of the results of emotional prosodic expression according to the specific emotions. The distribution of

Table 3 Distribution of errors by emotion on emotional prosodic expression task

\begin{tabular}{|c|c|c|c|c|c|}
\hline \multicolumn{2}{|c|}{$\begin{array}{l}\text { Number of subjects in each } \\
\text { group making } 0-5 \text { and } \\
6+\text { errors }\end{array}$} & Schizophrenics & Manics & Depressives & Normals \\
\hline \multicolumn{6}{|c|}{ False negatives (failure to identify designated emotion): } \\
\hline \multirow[t]{2}{*}{ Neutral } & $0-5$ errors & 9 & 14 & 11 & 13 \\
\hline & $6+$ errors & 6 & $i$ & 3 & 2 \\
\hline \multirow[t]{2}{*}{ Angry } & $0-5$ errors & 4 & 10 & 7 & 9 \\
\hline & $6+$ errors & 11 & 5 & 8 & 6 \\
\hline \multirow[t]{2}{*}{ Sad } & $0-5$ errors & 8 & 9 & 8 & 6 \\
\hline & $6+$ errors & 7 & 6 & 7 & 9 \\
\hline \multirow[t]{2}{*}{ Surprised } & $0-5$ errors & 8 & 8 & 14 & 11 \\
\hline & $6+$ errors & 7 & 7 & 1 & 4 \\
\hline \multicolumn{6}{|c|}{ False positives (actual emotion rated): } \\
\hline \multirow[t]{2}{*}{ Neutral } & $0-5$ errors & 0 & 2 & 3 & 3 \\
\hline & $6+$ errors & 15 & 13 & 12 & 12 \\
\hline \multirow[t]{2}{*}{ Angry } & $0-5$ errors & 14 & 14 & 15 & 15 \\
\hline & $6+$ errors & 1 & 1 & 0 & 0 \\
\hline \multirow[t]{2}{*}{ Sad } & $0-5$ errors & 13 & 13 & 12 & 14 \\
\hline & $6+$ errors & 2 & 2 & 3 & 1 \\
\hline \multirow[t]{2}{*}{ Surprised } & $0-5$ errors & 9 & 9 & 9 & 9 \\
\hline & $6+$ errors & 6 & 6 & 6 & 6 \\
\hline
\end{tabular}

subjects in each diagnostic group making 0-5 errors or six or more errors was chosen as the most appropriate method of presenting the results, because, summing the four raters' marks, the overall mean error rate per subject for each emotion was about five. An attempt was made to identify any unique profile of false negative errors on the various emotions within a diagnostic group by Chi-square analysis of errors within subject groups across the four emotions and within emotions across the four subject groups. The chief significant findings from these analyses were 1) schizophrenics, depressives and normal groups were worse at conveying anger than any other emotion; 2) within the emotions themselves schizophrenics and depressives were worst at conveying anger, manics and depressives were better than normal group at conveying sadness, and schizophrenics and manics were worst at conveying surprise. No statistical analysis of the false positives was carried out, although there appeared to be a trend for schizophrenics to be rated as more sad and for depressives to be rated as less angry than other groups.

\section{Discussion}

This study was concerned with examining the ability of schizophrenics, manics, depressives and normal groups to appreciate stress and emotion in the speech of others and to convey these in their own speech.

The first main finding was that all groups were relatively proficient, and roughly equivalent, in comprehending and conveying stress prosody. Manics were the most unusual group in this respect, in that they were the best of any group at conveying stress but the worst overall at identifying this in the sentences played to them. This suggests that despite the pressure of speech that many displayed, their articulation of words was not affected. Their poorer identification of stress in someone else's speech may stem from inattention as they performed worst of all groups, even more so than the schizophrenics, on a simple attention task involving cancellation of nominated digits given at the same time. ${ }^{12}$

The second main finding concerned the groups' performance on the two emotional prosody tasks. Here the situation was more complicated than in the case of stress. Overall, schizophrenics were worse than any other group on both tasks. But it was only on the emotional expression task that they were significantly worse than all the other groups. On the emotional comprehension task they were significantly worse than the normal group, but so were depressives and manics, and schizophrenics were not significantly worse than these last two groups.

A third subsidiary finding was that the pattern of the four subject groups' errors in identifying and conveying the four emotions tested here differed from one another in some respects. But differences were not prominent enough to justify us drawing any conclusions about a unique pattern in such a clinical condition. 
The main stimulus for this study had been the observation that the same claims made in the literature about a schizophrenic's difficulty in comprehending and expressing emotional prosody ${ }^{7}$ were also found in the neuropsychological literature on the effects of right hemisphere damage. ${ }^{23}$

Some support for the equivalence of schizophrenia and right hemisphere dysfunction in this respect can be found in our study from the two main findings outlined above. First, the preservation of stress prosody in schizophrenia is in keeping with an intact left hemisphere speech system, as stress prosody is generally considered to be a left hemisphere function. ${ }^{1}$ Secondly, the impairment in emotional prosody relative to normals in the case of expression and comprehension, and relative to depressives and manics in the case of expression only, is at least consistent with the presence of right hemisphere dysfunction in schizophrenia.

On the basis of our findings, we cannot say that right hemisphere dysfunction is uniquely present in schizophrenia and absent from the two affective groups. Both manics and depressives were significantly impaired, relative to normal subjects, in identifying the emotional tone of the speech. If this finding is substantiated by further investigation, it will provide further evidence for the claims of some authors that right hemisphere dysfunction can be found in mania ${ }^{13}$ and depressive illness ${ }^{14}$ as well as in schizophrenia. The issue of whether hemisphere imbalance of some sort plays a role in these affective psychoses and, if so, which hemisphere is the primary focus of the abnormality, is the subject of controversy. In the case of depression, there is some consensus that different varieties of depressive illness have a different pattern of hemisphere imbalance. According to Starkstein and Robinson ${ }^{15}$ a major depressive illness is more likely after a left anterior lesion, whereas a minor depressive illness can follow lesions to either hemisphere. According to Finset $^{16}$ a typical, psychotic depressive illness can occur after a left-sided lesion whereas an atypical neurotic depressive illness is more characteristic of right-sided damage.

Whatever the truth of these matters, our study at least calls into question the view, originally proposed by Flor-Henry, ${ }^{17}$ that schizophrenia is a consequence of only left hemisphere damage.

1 Emmorey KD. The neurological substrates for prosodic aspects of speech. Brain and Language 1987;30:305-20.

2 Tucker DM, Watson RT, Heilman KM. Discrimination and evocation of affectively intoned speech in patients with evocation of affectively intoned speech in patien
right parietal disease. Neurol 1977;27:947-50.

3 Ross ED. The aprosodias: functional-anatomic organization of the affective components of language in the right hemisphere. Arch Neurol 1981;38:561-9.

4 Bazhin EF, Korneva TV, Lomachenko AS. The ability of emotional perception in schizophrenic patients. In: Rieber $\mathrm{RW}$, ed. Applied psycholinguistics and mental health. New York: Plenum Press, 1980:78-9.

5 Novic J, Luchins DJ, Perline R. Facial affect recognition in schizophrenia. Is there a differential deficit? Brit J Psychiat 1984;144:533-7.

6 Todt EH, Howell RJ. Vocal cues as indices of schizophrenia. $J$ Speech Hear Res 1980;23:517-26.

7 Levin S, Hall JA, Knight RA, Alpert M. Verbal and nonverbal expression of affect in speech of schizophrenic and depressed patients. J Abnorm Psychol 1985;94:487-97.

8 Cutting J. The Psychology of Schizophrenia. Edinburgh Churchill Livingstone, 1985.

9 Cutting J. The right cerebral hemisphere and psychiatric disorders. Oxford: Oxford Univ Press, 1990.

10 Spitzer RL, Endicott J, Robins E. Research diagnostic criteria. New York: New York State Psychiatric Institute, 1975.

11 Nelson HE, O'Connell A. Dementia: the estimation of premorbid intelligence levels using the new adult reading test. Cortex 1978;14:234-44.

12 Cutting J, Murphy D. Impoverishment in the ability of schizophrenics, relative to manics or depressives, to appreciate the social norms of their culture. Brit J Psychiat In press).

13 Starkstein SE, Pearlson GD, Boston J, Robinson RG. Mania after brain injury. Arch Neurol 1987;44:1069-73.

14 Flor-Henry P. Cerebral Basis of Psychopathology. Bristol: John Wright, 1983.

15 Starkstein SE, Robinson RG. Affective disorders and cerebral vascular disease. Br J Psychiat 1989;154:170-82. 16 Finset $A$. Depressed mood and reduced emotionality after right-hemisphere brain-damage. In: Kinsbourne $\mathbf{M}$, ed. Cerebral hemisphere function in depression. Washington: American Psychiatric Press, 1988:49-64.

17 Flor-Henry P. Psychosis and temporal lobe epilepsy: a controlled investigation. Epilepsia 1969;10:363-95. 